\title{
Advanced Methods for Solving the Problems of Road Construction in Central Kazakhstan
}

\author{
Adil KADYROV, Vyacheslav KUNAEV, Ivan GEORGIADI, Rashid KHAIBULLIN
}

\begin{abstract}
Due to the poorly developed road network in Kazakhstan and the poor condition of the existing road communications, the issue of construction of new and reconstruction of existing roads is really crucial for the country. The article examines the problems of road construction in Central Kazakhstan, and proposes specific solutions to some of them. To reduce the construction cost of the subbase, the article suggests using a new building material instead of natural stone rubble. It is made of waste and by-products of manufacturing available in the region (blast-furnace slag and microsilica) hydrophobizated by used engine oil. Photos of the laboratory samples and the results of the experimental researches of this road-building material are attached to the article. To reduce the labour intensity of stiff and frozen soil excavation during the preparation of the subgrade, the article provides the use of a new working part of excavation machine. This working component is a cutterhead developed at the premises of The Karaganda State Technical University. The article deals with construction of this machine and principle of its operation.
\end{abstract}

Keywords: Central Kazakhstan; construction; cutterhead; excavation of stiff and frozen soils; road-building materials; slag-crushed stone

\section{INTRODUCTION}

From the Soviet Union, The Republic of Kazakhstan fell heir to a good network of highways. It was formed in the $60-70$ 's of the $20^{\text {th }}$ century when the road workers had the most advanced technics for that time. Road construction was actively pursued in the 70-80's so that by 1980 there were more than 117 thousand kilometres of roads in Kazakhstan. The condition of these roads became worse in the early 90's, after the collapse of the Soviet Union. To the beginning of the 2000's the road network of the country amounted to about 85 thousand kilometres, decreased by about a quarter.

The analysis of the situation in the country shows that the most significant problems of transport and road complex of Kazakhstan for today are:

- the backlog of the road network development,

- the territorial and the fuel and raw material potentials of the country contrary to the insufficient level road density,

- the discrepancy between the existing road network, which is the part of the international transport corridors, and the growth of international road transportation,

- the complexity and high labour intensity of the stiff and frozen soil excavation during the preparation of subgrade,

- the poor quality of the reconstructed and new roads along with the high costs of repair and construction.

To reduce the costs and to improve the quality of the reconstruction of existing roads and construction of new highways we suggest using more efficient excavation machines and new road-building material made of industrial waste. The economic expediency of the implementation of these solutions in the construction of roads in Central Kazakhstan was confirmed by the analytical and experimental researches.

\section{ANALYSIS OF EXISTING WAYS TO SOLVE THE PROBLEMS OF ROAD CONSTRUCTION}

Currently, many Kazakh and foreign scientists study problems of developing road construction technologies and mechanization (including D. A. Petrenko [1], S. M. Merdanov, M. Y. Spirichev, A. V. Sharuha, A. L. Egorov [2], A. S. Sedova [3], R. A. Kabashev, M. S. Kulgildinov, A. R. Zhappasov [4], J. J. Turgumbaev [5], R. Shteynmettsger [6], C. Nemmers [7]).

The targets of these researches are different. For example, D. A. Petrenko studies three-dimensional systems of computer-aided management using special technics of road construction [1] with a particular focus on methods of extracting initial information for the creation of $3 \mathrm{D}$ road models required for the operation of such systems.

S. M. Merdanov, M. Y. Spirichev, A. V. Sharuha, A. L. Egorov presented the results of the analysis of existing development trends in mechanization of winter roads construction. [2] They offered a modern power-operated complex and an updated technology of snow and ice road construction, which consists in enhancing of the roadbed layer-by-layer.

A. S. Sedova presented a methodology of the advanced technologies based on increasing of the completeness and reliability of information, substantiating project solutions for construction, repair and maintenance of roads [3]. This methodology is based on the prediction of the production response to the implementation of new technologies considering all the risks. The author performed the classification of factors that impede the effective implementation of advanced technologies by road organizations. She also developed a model of time management in technological process of road construction, as a measure of the duration and speed of its implementation.

J. J. Turgumbaev [5] and R. Shteynmettsger [6] presented the results of the analysis of efficiency and determination of the parameters of multi-purpose roadbuilding machines for excavation under given operating conditions.

R. A. Kabashev, M. S. Kulgildinov and A. R. Zhappasov in their work [4] presented the results of the research of physical and mechanical characteristics of the basic soils of Kazakhstan. They have also developed a method determining the perspective parameters of single bucket excavators during the construction of the road subgrade. 
Thus, among the most pressing issues of improving road construction technology considered by the listed researchers, we can identify a number of complex technical and economic problems, such as reducing costs, increasing the pace, efficiency and quality of road construction. These problems can be solved at the expense of wide implementation of new road-building machines, capable to provide quick pace and quality of work with minimum cost, new technological schemes and processes.

Changing of road construction technology allows achieving a significant reduction in costs and optimizing the technique of works (supporting the chosen costeffective option) [8].

\section{DEVELOPMENT OF A NEW ROAD-BUILDING MATERIAL FOR SUBBASE CONSTRUCTION}

Researches on the distribution costs of roads construction showed the following results. The cost of the subgrade construction is from 10 to $20 \%$ (during road construction in the mountains - up to $30 \%$ ), the cost of the subbase, base course and pavement is from 40 to $60 \%$, the cost of road furniture and engineering structures is from 20 to $25 \%$, the construction of temporary facilities and driveways is $10 \%$.

Thus, one of the most expensive elements of the road is a subbase. In addition, its characteristics have a huge impact on the final cost of cartage.

In its turn, the cost of the subbase depends on the cost of building materials $\mathrm{M}$, which includes:

- the selling price of the material manufacturer $P_{\text {sel, }}$,

- $\quad$ the markups of intermediary organizations $M_{\text {int }}$,

- the cost of container, packing and props $C_{\text {cont, }}$,

- the costs of delivering materials to the main warehouse, the construction object or enterprise for the preparation of semi-finished products $C_{\mathrm{del}}$,

- $\quad$ the warehouse expenses $E_{\mathrm{w}}$.

$M=P_{\mathrm{sel}}+M_{\mathrm{int}}+C_{\mathrm{cont}}+C_{\mathrm{del}}+E_{\mathrm{w}}$

A significant part of the crushed stone cost (used for subbase construction) is its selling price $P_{\text {sel }}$, including costs of extraction, processing, enrichment and costs of delivery to the construction object $C_{\mathrm{del}}$.

These two constituents of material cost can be significantly reduced by using industrial wastes of metallurgical production, which is located nearby to the construction object $[9,10]$ instead of natural stone materials. This way of reducing the cost of construction of roads is relevant for Central Kazakhstan because there is a large metallurgical enterprise in this region (JSC "Arcelor Mittal Temirtau). This enterprise has huge reserves of industrial wastes. As of 2017, there are about 20 million tons of blast furnace slag on the "Arcelor Mittal Temirtau". This material is used for the production of slag crushed stone. However, the use of the material in road construction is limited because of its high water absorption, insufficient cold resistance and strength caused by a significant amount of internal and external pores in this material. [11] Thus, the use of crushed stone obtained from blast furnace slag, without further treatment by water-repellent composition [12] is impractical because of the rapid destruction of such roads.
In order to improve the physical and mechanical characteristics of crushed stone made of blast furnace slag, we suggest the method of its sequential processing by means of microsilica, cement (pore placeholders, which increase the density and compressing strength of the material) and the used motor oil, performing the function of a surface hydrophobizator.

Microsilica is an ultrafine material consisting of particles of spherical shape. This material is made in the process of gas purification of furnaces producing silicon alloys [13]. In Central Kazakhstan, this material is produced as a by-product at LLP "Tau-Ken Temir", placed in the city of Karaganda, $30 \mathrm{~km}$ from the slag dump of JSC "Arcelor Mittal Temirtau".

The nearest enterprise for cement production of JSC "Central Asia Cement" is located in the Aktau township, $25 \mathrm{~km}$ from the slag dump of JSC "Arcelor Mittal Temirtau".

The used engine oil can be supplied from the neighboring service stations.

Thus, during the construction of new and reconstruction of existing roads in Central Kazakhstan the proposed material can be produced directly on the construction site. In this case, the delivery costs for raw materials would be minimal as there are several manufacturing enterprises in the region.

\section{EXPERIMENTAL STUDIES}

In order to confirm this hypothesis, we made experimental samples of the hydrophobized slag crushed stone (Fig. 1), having the following weight composition:

- dump waste blast furnace slag - 89,6\%;

- microsilika - 3,7\%;

- cement - 6,3\%;

- hydrophobic modifier made of the used motor oil $0,4 \%$.

The process flow of obtaining experimental samples consisted of 6 steps:

1) Cleaning the slag crushed stone of dust and clay particles;

2) Processing of the moistened slag crushed stone by dry microsilica powder;

3) Rewetting of the material surface;

4) Processing of the material by dry cement;

5) Dipping of the material into the spent motor oil for 3 hours;

6) Drying-out the finished material.

Preferable percentage of the components, technological sequence, and duration of the surface hydrophobization by the used motor oil were established empirically.

Under laboratory conditions, we compared the water absorption ability of ordinary slag crushed stones and new road-building material. For testing, we selected 5 samples of ordinary slag crushed stones and 5 samples of new material, all of them weighing about 2-2,5 kg. We cleaned all samples from friable particles and dust with metal brush and dried them out to the constant weight. 


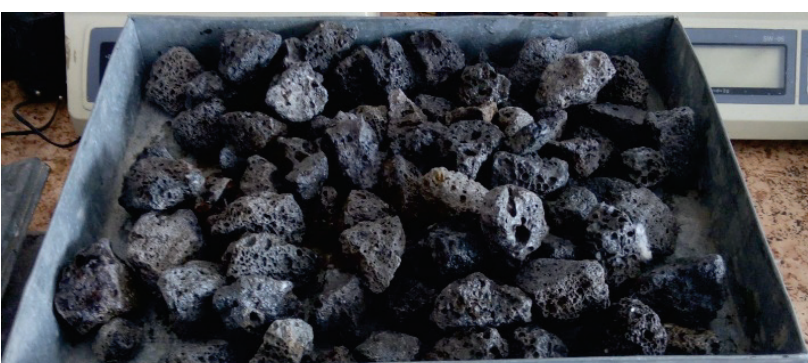

a)

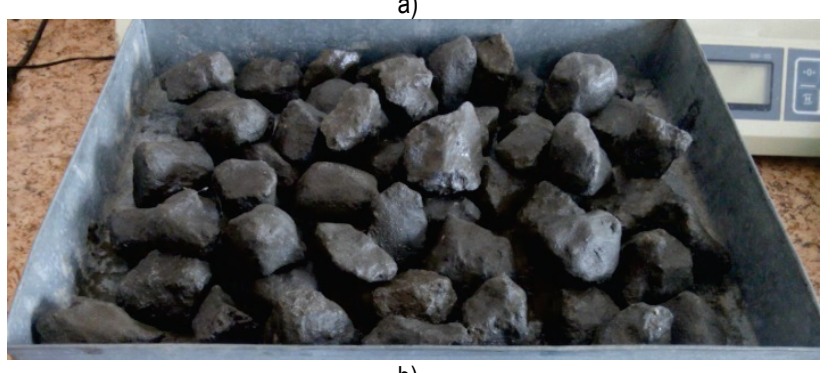

b)

Figure 1 Experimental samples of the crushed stone made of the blast furnace slag: a) before processing; b) after processing
The samples were placed into the reservoir with lukewarm water, and the water level in the reservoir was above the top of the samples no less than $20 \mathrm{~mm}$.

The samples were left in this position for 48 hours. Then we extracted samples from the vessel and sopped up moisture from their surface with a wrung damp cloth. Then each sample was weighed. The mass of water flowing out of the sample on the weighing pan was included in its mass. The results of these tests are presented in Tab. 1.

Based on the data gathered, we calculated the water absorption ability of each sample by mass $W$ using Eq. (2):

$W=\frac{m_{1}-m}{m} 100$,

The results of determination of the samples water absorption ability are presented in Tab. 2 .

The experiment showed that processing of slag crushed stone by the proposed method can reduce its water absorption ability significantly (on 3.93\%). Tests of the new material on the frost resistance take a long time and continue today.

Table 1 Masses of the experimental samples of the ordinary slag crushed stones and the proposed new road-building material

\begin{tabular}{|c|c|c|c|c|}
\hline \multirow{2}{*}{$\begin{array}{c}\text { Number of the } \\
\text { sample }\end{array}$} & \multicolumn{2}{|c|}{$\begin{array}{c}\text { Ordinary slag crushed stone } \\
\text { (without additional processing) }\end{array}$} & \multicolumn{2}{c|}{ New road-building material } \\
\cline { 2 - 5 } & Mass in dry condition $m(\mathrm{~g})$ & $\begin{array}{c}\text { Mass in water-saturated } \\
\text { condition } m_{1}(\mathrm{~g})\end{array}$ & Mass in dry condition $m(\mathrm{~g})$ & $\begin{array}{c}\text { Mass in water-saturated } \\
\text { condition } m_{1}(\mathrm{~g})\end{array}$ \\
\hline 1 & 2548 & 2694 & 2025 & 2052 \\
\hline 2 & 2385 & 2495 & 2351 & 2378 \\
\hline 3 & 2260 & 2372 & 2216 & 2244 \\
\hline 4 & 2276 & 2395 & 2127 & 2162 \\
\hline 5 & 2045 & 2159 & 2269 & 2293 \\
\hline
\end{tabular}

Table 2 Water absorption ability of the experimental samples of the ordinary slag crushed stones and the proposed new road-building material

\begin{tabular}{|l|c|c|c|c|c|c|}
\hline \multicolumn{1}{|c|}{ Sample type } & \multicolumn{5}{|c|}{ Water absorption by mass $W(\%)$} \\
\cline { 2 - 9 } & Sample 1 & Sample 2 & Sample 3 & Sample 4 & Sample 5 & $\begin{array}{c}\text { Average water } \\
\text { absorption }\end{array}$ \\
\hline $\begin{array}{l}\text { Ordinary slag crushed stones } \\
\text { (without additional processing) }\end{array}$ & 5,72 & 4,61 & 4,96 & 5,23 & 5,57 & 5,22 \\
\hline Proposed new road-building material & 1,33 & 1,15 & 1,26 & 1,65 & 1,06 & 1,29 \\
\hline
\end{tabular}

To determine the influence of the proposed method of processing slag crushed stone on the durability of a new material, we conducted experimental tests of the samples of conventional slag crushed stone and a new material for crushability. The crushability is determined by the degree of destruction of grains during compression (crushing) in the cylinder on a hydraulic press, with a maximum force of up to $500 \mathrm{kN}$.

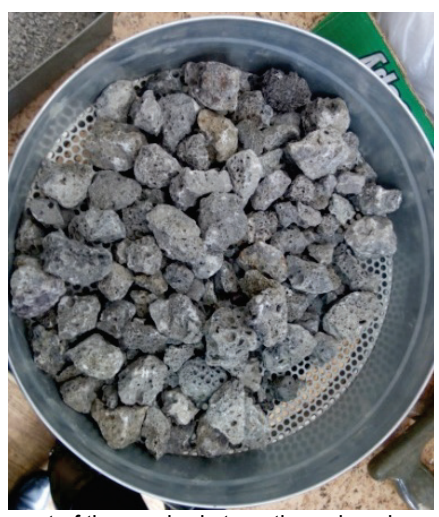

Figure 2 Sifting the rest of the crushed stone through a sieve with holes $5 \mathrm{~mm}$ in size
We prepared 5 samples of ordinary slag crushed stone and new road-building material, all of them weighing about 2-2,5 kg. Each sample of rubble was placed into a steel cylinder. Then the plunger was inserted into the cylinder in this way that its plate was at the level of the upper edge of the cylinder. Increasing the pressing force of the press by $1-2 \mathrm{kN}$ per second, we reached $200 \mathrm{kN}$. After compression, we poured out the test sample from the cylinder and weighed. Then each sample of crushed stone was sieved through a sieve with holes $5 \mathrm{~mm}$ in size (Fig. 2). The rest of the crushed stone was also weighed (Fig. 3).

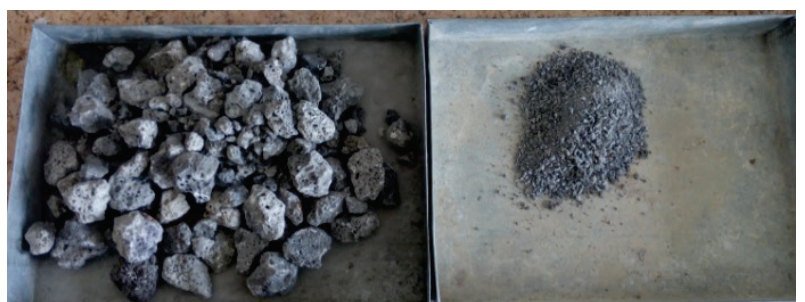

Figure 3 The rest of the crushed stone after crushing on a hydraulic press

The crushability of the material was calculated using Eq. (3): 
$C r=\frac{m_{c r 1}-m_{c r 2}}{m_{c r 1}} 100$

where $m_{c r 1}$ is mass of sample of crushed stone; $m_{c r 2}$ is mass of residue on the control sieve after sieving.

The results are presented in Tab. 3 .

The test results showed that the proposed method of processing slag crushed stone allows to reduce its crushability (and consequently to increase the durability) by $5.21 \%$.

To assess the water resistance of the oil film, which we applied to the slag crushed stone, we sank the samples in water for 48 hours and then removed from the water and dried. This procedure was repeated 10 times (10 cycles of drying and sinking into the water). This experiment showed that multiple sinking in water and drying of the material does not affect the state of the oil film. Water absorption remained at the initial level (about 1.3-1.4\%).

Our experimental and theoretical researches show that this material can be used in areas with frequent freezing and thawing of road pavement typical for the continental climate prevailing in Central Kazakhstan. Ultimately, the usage of the proposed material instead of the ordinary slag crushed stone leads to the long-term pavement performance with significant economy of financial resources that could be wasted in the case of using natural stone materials for their extraction, processing and delivery.

Table 3 Crushability of the experimental samples of the ordinary slag crushed stones and the proposed new road-building material

\begin{tabular}{|c|c|c|c|c|c|c|}
\hline \multirow[b]{2}{*}{ Sample type } & \multicolumn{6}{|c|}{ Crushability $C r(\%)$} \\
\hline & Sample 1 & Sample 2 & Sample 3 & Sample 4 & Sample 5 & $\begin{array}{c}\text { Average } \\
\text { crushability }\end{array}$ \\
\hline $\begin{array}{l}\text { Ordinary slag crushed stones } \\
\text { (without additional processing) }\end{array}$ & 29,51 & 30,24 & 31,35 & 29,23 & 30,8 & 30,23 \\
\hline Proposed new road-building material & 25,43 & 24,70 & 24,36 & 24,85 & 25,76 & 25,02 \\
\hline
\end{tabular}

\section{DESIGN OF A NEW WORKING TOOL FOR A DIGGING MACHINE}

The soils of seasonal freezing and stiff soils (including rocks) occupy a large part of the territory of Kazakhstan. Due to the climatic and geographical features of the country, the problem of frozen and stiff soils destruction while preparing the subgrade during road construction is crucial.

To solve this problem the scientists and researchers of the Karaganda State Technical University developed the attached equipment cutterhead RF-600 (Fig. 4) based on the single-bucket excavator. This equipment allows excavating soils and rocks of high strength.

The cutterhead, made on the basis of the hydraulic excavator EO-3322, EO-4121, EO-4321 (or another model of 3 or 4 dimensional group) can be used in the industrial sector, road and civil construction, in the process of digging foundation pits, trenches, recesses of different configurations, and for the road slopes formation, etc. The hydraulic excavator, which is the basic machine for installation of the attached equipment, has a movable boom and a grip. Thanks to these, the cutterhead allows making excavation work in confined spaces, as well as in hard to reach areas [14].

The cutterhead RF-600 is a removable equipment, which should be pivotally mounted upon the handle of a main excavator 1 , and it consists of two milling cutters (axially spaced) 4 , body 5 , bracket 2 , ladle 3 and the actuator 3 (Fig. 5).

The main unit of the cutterhead is its body, which serves as an oil bath for the conical and planetary gears. The bracket is fastened to the body by flange bolts. It connects the attached equipment with the handle of excavator.

A ladle that is attached to the bracket and adapted for removing loosened soil, may be set in one of two positions relative to the bracket (neutral and work). Each position of the ladle relative to the bracket is fixed by a special pin. The planetary gearbox and the conical gear are used to transmit torque from the axial-piston motor to milling cutters. Axial-piston motor is powered by an oil station of base excavator. [14]

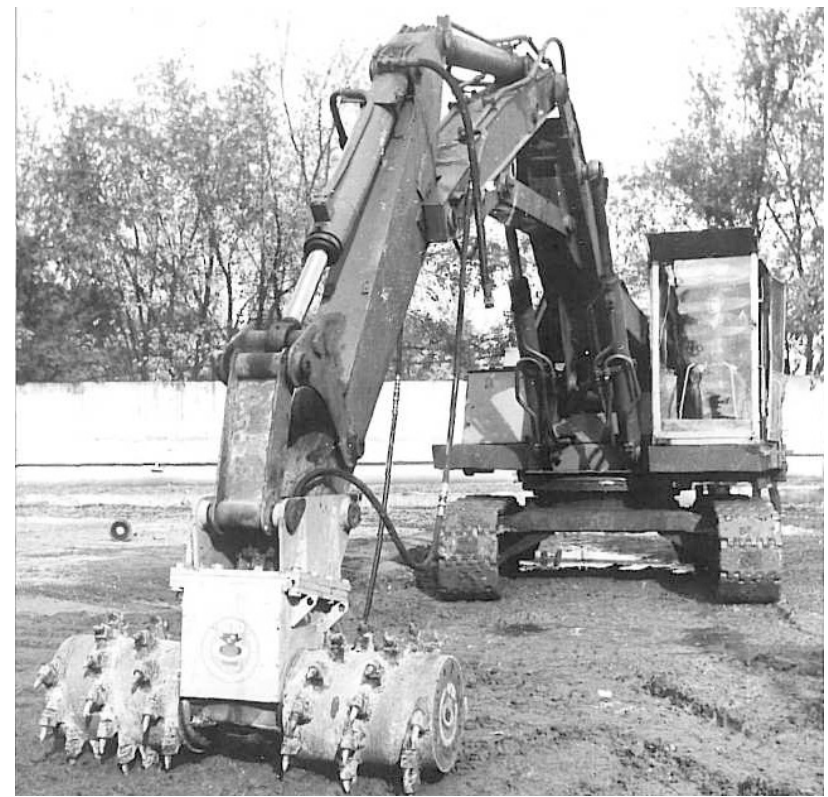

Figure 4 Full-size working model of the cutterhead RF-600

Operation of the cutterhead includes fiberwise digging of the array with further removal of loosened soil by the ladle 3 from the bottom. During the formation of road verges, while planning the surface for a certain point, the boom and the handle are drawn out. The rotating part of the excavator moves the cutterhead.

Penetration of the equipment into the soil and its translational movement along the loosening strip is performed due to the pressure force of cylinders of the boom and the handle.

The practical significance of the proposed cutterhead consists in the presence of the ladle for removing of the loosened soil from the bottom-hole space. It allows developing and transporting soil without additional technics [15]. Wide operating temperature range ( -40 to $+40{ }^{\circ} \mathrm{C}$ ) allows using the RF-600 model for excavating soil all year round in the conditions of a continental climate, which is relevant for the Central Kazakhstan. 


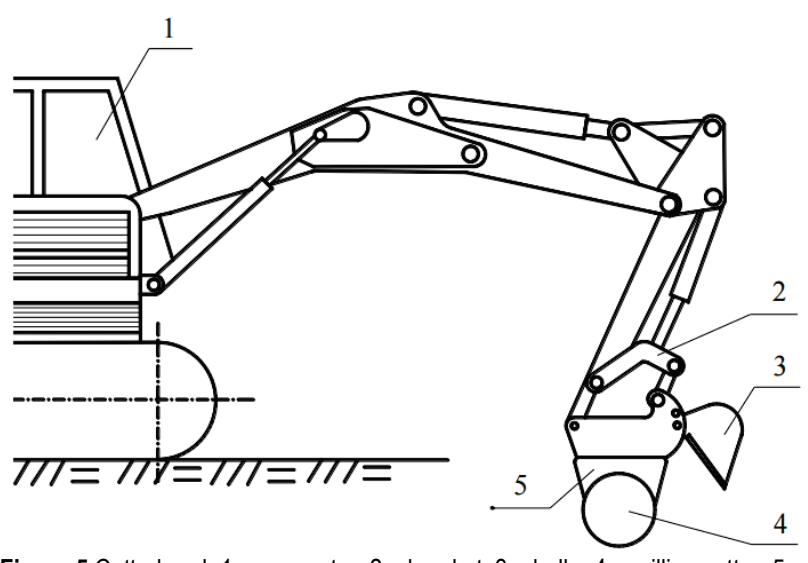

Figure 5 Cutterhead: 1 - excavator; 2 - bracket; 3 - ladle; 4 - milling cutter; 5 body

The prototype of a cutterhead, shown in Fig. 4 (RF600), was successfully tested in excavating frozen and stiff soils.

\section{CONCLUSION}

1) Among the problems of road construction in Central Kazakhstan one should place emphasis on high labor intensity of stiff and frozen soils excavation during subgrade preparation, poor quality of roads along with a high cost of construction caused by significant expenses for purchase and delivery of road-building materials.

2) In order to reduce the costs for delivery of roadbuilding materials we propose to use the hydrophobized slag crushed stone as a road building material in regions with developed metallurgical manufacturing. Laboratory tests of the obtained experimental samples of the material showed that the proposed method of surface hydrophobization can reduce water absorption from $5.22 \%$ to $1,29 \%$ (almost by factor of 5).

3) To reduce the labor intensity of excavation during the construction of roads the cutterhead structure was developed. This cutterhead is adapted for exploitation in a continental climate of Central Kazakhstan, and it has a ladle for removing loosened soil from the bottom-hole space, that allows developing and removing the soil without additional technics.

4) The systematic approach applied in the research reduces the cost and improves the quality of road construction due to addressing the specific tasks: developing of a new road-building material and a new working tool for an excavation machine.

\section{REFERENCES}

[1] Raikova, L. S. \&Petrenko, D. A. (2014). Road Construction based on 3D-models. CAD and GIS of Roads, 2(3). 81-85. https://doi.org/10.17273/CADGIS.2014.2.13

[2] Merdanov, S. M., Spirichev, M. J., Sharuha, A. V., \& Egorov, A. L. (2013). Technology of ice and snow road construction. Modern problems of science and education, 5, 32-38.

[3] Sedova, A. S. (2010). Design of applying the advanced technologies in construction, repair and maintenance of roads. The Voronezh State University of Architecture and Civil Engineering, Volgograd.
[4] Kabashev, R. A., Kulgildinov, M. S., \& Zhappasov, A. R. (2000). Subgrade of highways of the Republic of Kazakhstan. Proceedings of the $1^{\text {st }}$ Central Asian Geotechnical Symposium / Astana, 200-203.

[5] Turgumbaev, J. J., Nedorezov, I. A., \& Frolov, I. O. (2001). Evaluating of the effectiveness of road construction machines. Mechanization of Construction, 1, 23-27.

[6] Shtejnmetcger, R. (1981). Analysis, Evaluation of the effectiveness and determination of the parameters of multipurpose machines for the excavation of small volumes in the given operating conditions. Moscow.

[7] Nemmers, C. J. (1997). Recycling for road improvements. Proceedings of the International Conference on the Environment and Technical Implications of Construction with Alternative Materials / Houthem St. Gerlach, the Netherlands, 105-114. https://doi.org/10.1016/S0166-1116(97)80196-3

[8] Gorelyshev, N. V., Polosin-Nikitin, S. M., \& Koganzon, M. S. (1992). Technology and organization of construction of highways: A Textbook for high schools. Transport, Moscow.

[9] Ahmed, I. (1993). Use of waste materials in highway construction. Noyes Data Corporation, New Jersey.

[10] See, L. S. \& Hamzah, M. O. (2002). Processed steel slag for road construction industry. Fifth Malaysian Road Conference / Kuala Lumpur, 71-75.

[11] Kadyrov, A. S. \& Kunaev, V. A. (2016). Developing of technology and mechanization means for obtaining of waterproof building material on the basis of blast furnace slag. Proceedings of the International Scientific and Practical Conference: Science, Technical Regulations and Engineering in the Construction: Condition and Prospects / KSTU, Karaganda, 258-260.

[12] Higerovich, M. I. \& Bayer, V. E. (1979). Hydrophobicplasticizing additives for cements, mortars and concretes. Stroyizdat, Moscow.

[13] Usherov-Marshak, A. V. (2009). Research of concretes: lexicon. RIF Building Materials, Moscow.

[14] Kadyrov, A. S. \& Kurmasheva, B. K. (2009). Developing of Cutterheads. International Scientific Journal, 9(43), 56-58.

[15] Kadyrov, A. S. \& Kabashev, R. A. (1999). The basics of loading of milling and drilling machines. KSTU, Karaganda.

\section{Contact information:}

Adil KADYROV, PhD, Prof.

Karaganda State Technical University,

Department of Transport Technics and Logistics Systems,

Krivoguz street, 86, 100000, Karaganda, Kazakhstan

E-mail: irina.adilevna@gmail.com

\section{Vyacheslav KUNAEV, PhD}

(Corresponding author)

Karaganda State Industrial University,

Department of Technological Machines and Transport,

Shkolnaya street, 7-15, 101402, Temirtau, Kazakhstan

E-mail: kunaev91kz@gmail.com

\section{Ivan GEORGIADI, MSc}

Karaganda State Technical University,

Department of Transport Technics and Logistics Systems,

Zelenaya street, 24, 101400, Temirtau, Kazakhstan

E-mail: deputat-georgiadi@mail.com

Rashid KHAIBULLIN, PhD, Prof.

Karaganda State Technical University,

Department of Industrial Transport named prof. A.N. Daniyarov,

Lenin street, 61/2-19, 100017 Karaganda, Kazakhstan

E-mail: medtex2000@mail.ru 